\title{
Desempenho de porcas alimentadas durante a gestação, do primeiro ao terceiro parto, com rações com diferentes níveis de proteína bruta
}

\author{
Kedson Raul de Souza Lima1, Aloízio Soares Ferreira², Juarez Lopes Donzele ${ }^{2}$, Maria Cristina \\ Manno ${ }^{3}$, Diogo Araújo ${ }^{4}$, Horacio Santiago Rostagno ${ }^{2}$, Francisco Carlos Oliveira Silva ${ }^{5}$ \\ 1 UFRA - Belém, PA \\ 2 UFV - Viçosa, $M G$. \\ ${ }^{3}$ Mestre em Zootecnia - UFV. \\ 4 Graduação em Agronomia - UFV. \\ ${ }^{5}$ EPAMIG - Viçosa, MG.
}

RESUMO - Foram utilizadas 30 porcas mestiças $(118,18 \pm 12,2 \mathrm{~kg}$, espessura de toucinho de 13,82 $\pm 1,42 \mathrm{~mm}$ e 220 dias de idade) distribuídas em um fatorial 3 × 3 com parcelas subdivididas com dez repetições, em um delineamento inteiramente ao acaso, em que as ordens de parto constituíram as parcelas e os níveis de proteína, as subparcelas. Foram avaliados os efeitos da inclusão de três níveis de PB $(10,0 ; 13,5$ e 17,0\%) na ração durante a gestação sobre o desempenho das fêmeas em três ciclos reprodutivos sucessivos completos. O ganho de peso da porca na gestação foi influenciado pelo nível de proteína na dieta de gestação, mas não pela ordem de parto. O ganho em ET durante a gestação e a perda durante a lactação não foram influenciados significativamente pelos níveis de PB da ração e pela ordem de parto. A eficiência energética não diferiu entre os tratamentos nem conforme a ordem de parto. A ordem de parto afetou o peso médio da leitegada ao nascimento (PMLN), o peso médio da leitegada ao desmame (PMLD), o número de leitões nascidos totais (NT) e nascidos vivos (NV) e o número de leitões desmamados (ND). O desempenho da leitegada para ganho médio diário do leitão (GDP) não variou entre os tratamentos. O peso relativo (\%) não sofreu efeito de nenhum dos fatores estudados. O consumo de ração (CR) durante a lactação e o intervalo desmame-cobertura (IDC) foram influenciados pelos tratamentos, sendo que o CR foi afetado também pela ordem de parto. Independentemente da ordem de parto, o nível de $17 \%$ de PB proporcionou o melhor ganho de tecido corporal durante a gestação e o menor IDC, enquanto o nível de $10 \%$ promoveu o maior consumo de ração. A ordem de parto influenciou o NT, NV, GPP, PMLN e PMLD, que foram melhores no terceiro parto.

Palavras-chave: espessura de toucinho, ganho de peso da fêmea, intervalo desmame-cobertura, lactação

\section{Effects of feeding different dietary crude protein levels on performance of sows during pregnancy, from the first to third parturition}

\begin{abstract}
Thirty crossbred sows averaging $118.18 \pm 12.2 \mathrm{~kg}$ of BW, backfat thickness of $13.82 \pm 1.42 \mathrm{~mm}$ and 220 days old were assigned to a completely randomized design in a split plot scheme with 10 replicates and parturition orders included in the plots ( 3 x 3 factorial arrangement) and CP ingestion levels (10.0, 13.5, and 17.0\%) in the sub-plots. The effects of dietary $\mathrm{CP}$ ingestion levels on female performance in three complete successive reproductive cycles were evaluated during the pregnancy. Sow weight gain in the pregnancy was affected only by dietary protein levels in the gestation. No significant effect of both dietary protein level and parturition order on BT gain during the pregnancy and the loss during the lactation was observed. Neither treatments nor parity orders affected energy efficiency. Average litter weight at birth, average litter weight at weaning, number of total piglets born (NTPB) and born alive (BA) and number of weaned pigs were affected by parity order. Litter performance for daily average weight gain (DAWG) of piglet did not vary among the treatments. No treatment effect on the relative weight (\%) was observed. Feed intake (FI) during the lactation and weaning-mating interval (WMI) were affected by the treatments, and FI was affected only by parity order. The $17 \% \mathrm{CP}$ level resulted in better body tissue gain during the pregnancy and lower WMI and the $10 \% \mathrm{CP}$ level the highest feed intake, and that was independent of parity order. The parity order affected NTPB and BA, litter DAWG and WMI, that were greater in the third parity.
\end{abstract}

Key Words: backfat thickness, female weight gain, lactation, weaning-mating interval

\section{Introdução}

A influência da nutrição da fêmea suína sobre sua produção e reprodução pode ser considerada um sistema de saída e entrada de nutrientes, ou seja, de absorção e produção de leitões, medido pelo número de leitões produzidos/ fêmea/ano em relação à quantidade de nutrientes ingeridos pela matriz. Todavia, a nutrição destes animais deve ser 
vista de forma mais complexa, considerando não somente seus efeitos no desempenho, mas também seu impacto no bem-estar, na poluição ambiental, no manejo de dejetos, no status sanitário e na qualidade do produto. Portanto, a nutrição de fêmeas suínas tornou-se uma área de estudo integrada e pró-ativa que reflete diretamente as funções relacionadas à sua produtividade.

A produtividade da porca tem aumentado ao longo dos anos. Em 1991, 1/3 das melhores granjas canadenses desmamava 22,25 leitões/porca/ano, desempenho que, uma década ante, era atingido em pouquíssimas criações. Com esta produtividade, é possível deduzir que, uma década atrás, as exigências nutricionais de fêmeas suínas eram diferentes das atuais (Patience, 1996).

Considerando que os níveis de nutrientes devem ser providos em cada estádio de gestação, falhas no processo produtivo podem ter conseqüências variáveis na taxa de crescimento, no desenvolvimento dos fetos no útero, no peso do leitão ao nascimento, nas próprias reservas corporais e no desempenho subseqüente. No ciclo produtivo das porcas, as reservas são depositadas somente na gestação e são muito dependentes do status metabólico e da ingestão de nutrientes, principalmente de aminoácidos, pela porca durante esta fase (Close \& Cole, 2001).

Definir o melhor programa alimentar para o rebanho parece ser um grande desafio, haja vista a diversidade das condições ambientais, do potencial genético e do sistema de manejo adotado na indústria. Aumentando este desafio, destaca-se a mudança na natureza da fêmea durante consecutivos ciclos reprodutivos de gestação e lactação, quando se aproxima do peso adulto. Essas mudanças modificam suas exigências e seus desempenhos produtivo e reprodutivo. Além disso, essas exigências podem variar conforme a linhagem genética, a raça, a idade, a ingestão de energia, entre outros fatores. Com a seleção genética para deposição de massa muscular, tem-se verificado que o metabolismo de proteína em fêmeas gestantes e suas exigências para aminoácidos essenciais se altera. Por exemplo, o potencial de acréscimo de proteína diminui com a idade, à medida que o animal atinge a taxa máxima de deposição, de modo que o consumo maior de energia pode aumentar a deposição protéica, elevando também as exigências de aminoácidos (Pettigrew \& Yang, 1997).

O perfeito entendimento das quantidades diárias de nutrientes necessárias para o máximo desempenho das porcas e o controle constante do consumo diário de nutrientes possibilitariam a formulação adequada de rações para garantia do sucesso na produção de suínos (Lima \& Viola, 1998).

Existem poucos estudos sobre o efeito da ingestão de proteína em fêmeas suínas de alto potencial para deposição de carne e estes apresentam resultados variáveis, principalmente quando considerados vários ciclos reprodutivos. Neste contexto, objetivou-se avaliar os efeitos da ingestão de PB durante a gestação, do primeiro ao terceiro parto, sobre os desempenhos produtivo e reprodutivo de porcas.

\section{Material e Métodos}

O trabalho foi realizado na Universidade Federal de Viçosa - MG, no Setor de Suinocultura do Departamento de Zootecnia (DZO), durante os meses de maio de 2001 a dezembro de 2002.

Foram utilizadas, inicialmente, 30 fêmeas mestiças (peso inicial de $118,7 \pm 12,2 \mathrm{~kg}$, espessura de toucinho (ET) de $13,82 \pm 1,42 \mathrm{~mm}$ e 220 dias de idade) distribuídas em um delineamento inteiramente casualizado, em parcela subdividida, com dez repetições. Nas parcelas, foram distribuídas as ordens de parto e nas subparcelas, os níveis de proteína, considerando um animal por unidade experimental.

As rações experimentais (isoenergéticas, isovitamínicas e isominerálicas - Tabela 1) foram obtidas a partir de rações formuladas em acordo com recomendações do NRC (1998), exceto quanto aos níveis de $\mathrm{PB}$. A ração com nível mais elevado de PB (17\%) foi diluída com amido de milho, de forma a se manter constante a relação milho e farelo de soja, para manutenção da relação aminoacídica das três rações experimentais e, portanto, da mesma qualidade da proteína.

A ração de lactação das fêmeas foi formulada para conter $0,9 \%$ de lisina total, excedendo a recomendação do NRC (1998), de 0,6\% de lisina total.

Durante a gestação, as marrãs foram alimentadas individualmente com 2,0 kg de ração/dia (fracionados em duas vezes - manhã e tarde) até atingirem 110 dias de prenhez, quando receberam quantidade de $3 \mathrm{~kg}$ de ração de lactação até o parto. A cada ciclo reprodutivo, a quantidade de ração de gestação foi acrescida em $96 \mathrm{~g}$, conforme descrito por Mahan (1998), ou seja, 2,00; 2,096 e 2,192 kg, respectivamente, no $1 \underline{0}, 2 \underline{0}$ e $3 \underline{0}$ partos. Para avaliação do efeito dos tratamentos na gestação na fase de lactação, todas as porcas receberam, durante a amamentação, a mesma dieta (Tabela 2).

$\mathrm{Na}$ fase de lactação, o fornecimento de ração foi feito na quantidade de $1 \mathrm{~kg}$ no primeiro dia, aumentando gradativamente até atingir máximo consumo, esperado para a primeira semana pós-parto. Para maior eficiência no consumo, a ração foi fornecida três vezes ao dia. As leitegadas foram equalizadas em número de nove, nove e

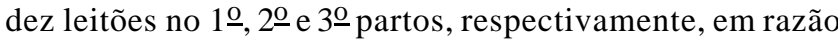
da média de leitões inicialmente ajustada conforme o número de leitões nascidos por fêmea. 
Tabela 1 - Composição centesimal das rações experimentais Table 1 - Ingredient composition of the experimental diets

\begin{tabular}{|c|c|c|c|}
\hline \multirow[t]{2}{*}{$\begin{array}{l}\text { Ingrediente } \\
\text { Ingredient }\end{array}$} & \multicolumn{3}{|c|}{$\begin{array}{c}\text { Nível de proteína bruta (\%) } \\
\text { Crude protein level }(\%)\end{array}$} \\
\hline & 10,0 & 13,5 & 17,0 \\
\hline Farelo de soja (45\% PB) & 14,20 & 19,42 & 24,63 \\
\hline $\begin{array}{l}\text { Soybean meal }(45 \% \text { CP }) \\
\text { Milho }(8,5 \% \mathrm{~PB}) \\
\text { Corn }(8.5 \% \mathrm{CP})\end{array}$ & 39,70 & 54,30 & 68,77 \\
\hline $\begin{array}{l}\text { Amido } \\
\text { Starch }\end{array}$ & 37,95 & 19,44 & 1,00 \\
\hline Óleo de soja & 1,50 & 1,50 & 1,50 \\
\hline $\begin{array}{l}\text { Soybean oil } \\
\text { Calcário } \\
\text { Limestone }\end{array}$ & 0,86 & 0,88 & 0,90 \\
\hline $\begin{array}{l}\text { Fosfato bicálcico } \\
\text { Dicalcium phosphate }\end{array}$ & 2,12 & 2,00 & 1,88 \\
\hline Sal & 0,45 & 0,43 & 0,41 \\
\hline $\begin{array}{l}\text { Salt } \\
\text { Mistura mineral } \\
\text { Mineral mix }\end{array}$ & 0,05 & 0,05 & 0,05 \\
\hline $\begin{array}{l}\text { Mistura vitamínica } \\
\text { Vitamin mix }\end{array}$ & 0,10 & 0,10 & 0,10 \\
\hline Antioxidante & 0,01 & 0,01 & 0,01 \\
\hline $\begin{array}{l}\text { Antioxidant } \\
\text { Areia lavada } \\
\text { Washed sand } \\
\text { Total (kg) }\end{array}$ & 3,06 & 1,87 & 0,66 \\
\hline \multicolumn{4}{|l|}{$\begin{array}{l}\text { Composição calculada } \\
\text { Calculated composition }\end{array}$} \\
\hline Proteína bruta (\%) & 10,00 & 13,50 & 17,00 \\
\hline $\begin{array}{l}\text { Crude protein } \\
\text { Cálcio }(\%)\end{array}$ & 0,910 & 0,910 & 0,910 \\
\hline $\begin{array}{l}\text { Calcium } \\
\text { Energia digestível }(\mathrm{kcal} / \mathrm{kg}) \\
\text { Digestible energy }\end{array}$ & 3.400 & 3.400 & 3.400 \\
\hline Fósforo total (\%) & 0,570 & 0,615 & 0,659 \\
\hline $\begin{array}{l}\text { Total phosphorus } \\
\text { Fósforo disponível (\%) }\end{array}$ & 0,450 & 0,450 & 0,450 \\
\hline $\begin{array}{l}\text { Available phosphorus } \\
\text { Lisina total }(\%) \\
\text { Lysine }\end{array}$ & 0,494 & 0,676 & 0,858 \\
\hline $\begin{array}{l}\text { Metionina }+ \\
\text { cistina total }(\%)\end{array}$ & 0,327 & 0,448 & 0,568 \\
\hline Total methionine + cystine & & & \\
\hline $\begin{array}{l}\text { Relação lisina/met+cistina } \\
\text { Lysine and met }+ \text { cis ratio }\end{array}$ & 66,2 & 66,2 & 66,2 \\
\hline Treonina total $(\%)$ & 0,384 & 0,525 & 0,666 \\
\hline $\begin{array}{l}\text { Total threonine } \\
\text { Triptofano total }(\%) \\
\text { Total tryptophan }\end{array}$ & 0,116 & 0,159 & 0,202 \\
\hline $\begin{array}{l}{ }^{1} \text { Composição por kg de produ } \\
\text { Co }-1.000 \mathrm{mg} \text {; Cu }-10.000 \mathrm{n} \\
{ }^{2} \text { Composição por } \mathrm{kg} \text { de prod } \\
8.500 .000 \text { Ul, vit. } \mathrm{D}_{3}-1.300 \\
\mathrm{mg} \text {, tiamina (tiamin) }-2.000 \mathrm{mg} \\
\text { (piridoxin) - } 1.600 \mathrm{mg} \text {, vit. } \mathrm{B}_{12} \\
\text { pantotenato de cálcio (calciun } \\
120 \mathrm{mg} \text {, Se }-150 \mathrm{mg} \text {, BHT - }\end{array}$ & $\begin{array}{l}\text { o (compositio } \\
\text { g; Zn - } 10.0 \\
\text { uto (compos } \\
000 \text { Ul, vit. } \\
\text { riboflavina } \\
25.000 \mathrm{mo} \\
\text { pantothenate, }\end{array}$ & $\begin{array}{l}\mathrm{kg} \text { of produc } \\
\mathrm{mg} ; \mathrm{Mn}-40 \\
\text { per } \mathrm{kg} \text { of pro } \\
20.000 \mathrm{mg} \\
\text { flavin) }-5.000 \\
\text { iacina (niaci } \\
5.000 \mathrm{mg} \text {, }\end{array}$ & $\begin{array}{l}-1.500 \mathrm{mg} \text {; } \\
00 \mathrm{mg} ; \\
\text { t): vit. A } \\
\text { t. } \mathrm{K}_{3}-2.000 \\
\text { g, piridoxina } \\
40.000 \mathrm{mg} \text {, } \\
\text { tina (biotin) - }\end{array}$ \\
\hline
\end{tabular}

$120 \mathrm{mg}$, Se $-150 \mathrm{mg}$, BHT - $30.000 \mathrm{mg}$.

Durante o experimento (inverno e verão), foram medidas as variações climáticas (temperatura ambiente máxima e mínima, de bulbo úmido e de bulbo seco e temperatura de globo negro) para explicar possíveis modificações no con-
Tabela 2 - Composição centesimal da ração de lactação Table 2 - Ingredient composition of the lactating diet

\begin{tabular}{lc}
\hline $\begin{array}{l}\text { Ingrediente } \\
\text { Ingredient }\end{array}$ & $\begin{array}{c}\text { Quantidade } \\
\text { Amount }\end{array}$ \\
\hline Farelo de soja (45\% PB) (Soybean meal) & 23,30 \\
Milho (8,5\% PB) (Corn) & 70,78 \\
Óleo de soja (Soybean oil) & 2,00 \\
Calcário (Limestone) & 0,82 \\
Fosfato bicálcico(Dicalcium phosphate) & 2,40 \\
Sal (Salt) & 0,50 \\
Suplemento mineral ${ }^{1}$ (Mineral mix) & 0,05 \\
Suplemento vitamínico ${ }^{2}$ (Vitamin mix) & 0,10 \\
Cloreto de colina(Choline chloride) & 0,04 \\
Antioxidante (Antioxidant) & 0,01 \\
Total (kg) & 100,00 \\
\hline
\end{tabular}

Composição calculada

Calculated composition

Proteína bruta $(\%)$ (Crude protein) $\quad 17,64$

Cálcio $(\%)$ (Calcium) $\quad 0,97$

Energia digestível (kcal/kg) (Digestible energy) $\quad 3.450$

Fósforo total (\%)(Total phosphorus) $\quad 0,65$

Fósforo disponível (\%) (Available phosphorus) $\quad 0,43$

Lisina total (\%) (Total lysine) $\quad 0,90$

Metionina + cistina (\%)(Methionine + cystine $) \quad 0,56$

Sódio (\%) (Sodium) $\quad 0,22$

Treonina (\%) (Threonine) $\quad 0,69$

Triptofano (\%)(Tryptophan) 0,21

${ }^{1}$ Composição por $\mathrm{kg}$ de produto (composition per $\mathrm{kg}$ of product): I $-1.500 \mathrm{mg}$,

Co $-1.000 \mathrm{mg}, \mathrm{Cu}-10.000 \mathrm{mg}, \mathrm{Zn}-10.000 \mathrm{mg}, \mathrm{Mn}-40.000 \mathrm{mg}$.

${ }^{2}$ Composição por $\mathrm{kg}$ de produto (composition per $\mathrm{kg}$ of product): vit. A $8.500 .000 \mathrm{UI}$, vit. $\mathrm{D}_{3}-1.300 .000 \mathrm{UI}$, vit. E - $20.000 \mathrm{mg}$, vit. $\mathrm{K}_{3}-2.000 \mathrm{mg}$, tiamina (tiamin) $-2.000 \mathrm{mg}$, riboflavina (riboflavin) $-5.000 \mathrm{mg}$, piridoxina (piridoxin) $-1.600 \mathrm{mg}$, vit. $\mathrm{B}_{12}-25.000 \mathrm{mcg}$, niacina (niacin) $-40.000 \mathrm{mg}$, pantotenato de cálcio (calcium pantothenate) $-15.000 \mathrm{mg}$, biotina (biotin) $120 \mathrm{mg}$, Se $-150 \mathrm{mg}$, antioxidante (antioxidant) $-30.000 \mathrm{mg}$.

sumo de ração e no desempenho nas duas fases (gestação e, principalmente, lactação).

O aparecimento de cio nas marrãs foi observado no mínimo duas vezes ao dia, utilizando-se um macho adulto e experiente no momento da observação para assegurar a melhor identificação do cio. As marrãs foram inseminadas

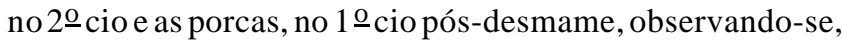
desde o $3 \underline{o}$ dia pós-desmame, o tempo para retorno ao cio. Quando ocorreram falhas na concepção, a fêmea foi submetida novamente à cobrição, seguindo-se com o ciclo normalmente. Somente foram descartados animais com problemas de saúde, locomoção, anestro ou que retornaram ao cio por mais de duas vezes. Foram utilizados três machos meioirmãos para coleta de sêmen durante todo o período experimental. O sêmen foi diluído com o diluente Beltsville - TS (BTS) (Pusel \& Jonhston, 1975).

As fêmeas foram alojadas individualmente em gaiolas de gestação, onde foram mantidas até os 110 dias de gestação. Após esse período, foram lavadas com água e sabão e encaminhadas para as celas parideiras na maternidade, onde foram mantidas até os 21 dias (desmame) pós-parto. 
Em razão da grande variabilidade de consumo entre os leitões, não foi fornecida ração no período de aleitamento, embora tivessem livre acesso ao comedouro da fêmea.

As fêmeas gestantes foram pesadas à cobertura e aos $30,60,90$ e 110 dias de gestação, enquanto as porcas lactantes e as leitegadas foram pesadas nas 24 horas após o parto e aos 7, 14 e 21 dias pós-parto. Na primeira pesagem após o parto (24 horas), efetuaram-se a marcação e o corte dos dentes e da cauda dos leitões. A espessura de toucinho das matrizes foi medida nesses mesmos intervalos após o parto, a $6,5 \mathrm{~cm}$ da coluna vertebral, entre a penúltima e a última costela (ponto P2), utilizando-se o instrumento de ultra-som digital numérico.

Durante o período desmame-cobertura, as fêmeas foram alojadas em piquetes de terra para se recuperar de possíveis lesões nos cascos e receberam, durante este intervalo, ração de lactação na quantidade de até $3,0 \mathrm{~kg} /$ dia.

O desempenho da fêmea foi avaliado pelos seguintes parâmetros produtivos: ganho de peso durante a gestação (da cobertura aos 60 dias de gestação, da cobertura aos 90 dias de gestação, da cobertura aos 110 dias de gestação, dos 90 aos 110 dias de gestação e da cobertura ao pósparto); ganho em espessura de toucinho; peso médio da leitegada e do leitão ao nascimento; peso médio do leitão e da leitegada ao desmame; ganho de peso diário do leitão e da leitegada; perda de peso durante a lactação; consumo de alimento; variação no peso corporal (peso relativo); perda em espessura de toucinho no intervalo desmame-cio.

O ganho de peso da fêmea na gestação foi avaliado pela covariável peso à cobertura e o peso do leitão ao nascimento, pela covariável número de nascidos vivos. Como durante a lactação geralmente há perdas de peso e os números se tornam negativos (dificulta a análise estatística em virtude da grande variação), foi necessário transformar os números relacionados a perdas em porcentagem, ou seja, em valores relativos, que foram chamados de mudanças no peso corporal ou na espessura de toucinho.

Verificou-se também a eficiência energética da fêmea durante a gestação, assumindo-se (Close \& Cole, 2001) que a composição corporal normal é de $17 \%$ de proteína, $56 \%$ de água e $24 \%$ de lipídios e que cada quilo de perda de peso na lactação proveria 13,6 MJ de energia. Considerou-se ainda eficiência de mobilização de tecido de $0,88 \%$, o que corrigiu o valor da energia de $1 \mathrm{~kg}$ de peso perdido na lactação para 12,0 MJ de ED.

As observações referentes ao j-ésimo nível do tratamento $(j=1,2$ e 3$)$, medidas na i-ésima ordem de parto $(i=1$, 2 e 3) observada na k-ésima unidade experimental, foram analisadas em delineamento inteiramente casualisado, adotando a estrutura de parcelas subdivididas com os níveis do fator ordem de parto e tratamento compondo a parcela e os níveis do fator tratamento compondo as subparcelas. O modelo estatístico pode ser representado algebricamente como:

$$
y_{i j k}=\mu+\alpha_{i}+d_{i k}+\tau_{j}+(\alpha \tau)_{i j}+e_{i j k}
$$

em que: $\mathrm{y}_{\mathrm{ijk}}=$ resposta do tempo k-ésimo animal, no j-ésimo tratamento, nai-ésima ordem de parto; $\mu=$ média geral; $\alpha_{i}=$ efeito fixo da ordem de parto i; $d_{i k}=$ efeito aleatório do erro da parcela; $\tau_{j}=$ efeito fixo do tratamento $;(\alpha \tau)_{i j}=$ efeito da interação ordem de parto $\mathrm{i} \times$ tratamento $\mathrm{j}$; e $\mathrm{e}_{\mathrm{ijk}}=$ erro aleatório associado a cada observação. Para testar a hipótese de nulidade sobre os efeitos do fatores ordem de parto, tratamento e interação ordem de parto $\times$ tratamento, adotou-se o nível de 0,05 de significância. Em caso de rejeição da hipótese de nulidade, a discriminação das diferenças entre os níveis do fator foi realizada pelo teste Student Newman Kells (SNK), também a 0,05 de probabilidade.

Para a variável perda de espessura de toucinho (PET), foi realizada uma mudança de escala utilizando-se logaritmo para aproximar uma distribuição próxima da normalidade. Após correção, a variávelfoi chamada PET corrigido. Para as análises, utilizou-se o programa computacional SAS (2001).

\section{Resultado e Discussão}

As médias das temperaturas mínima e máxima dentro das instalações no período foram de 18,0 e $24^{\circ} \mathrm{C}$, respectivamente. A umidade relativa média (UR\%) foi de 70,0\% e o índice de temperatura de globo negro e umidade (ITGU) medido no mesmo intervalo foi de 66,0 , o que, segundo Baêta et al. (1987), caracteriza ambiente de conforto térmico para estes animais.

Não foi observado efeito significativo $(\mathrm{P}>0,05)$ da interação níveis de $\mathrm{PB}$ da ração $\times$ ordens de partos avaliadas para o ganho de peso (GP) e o ganho em espessura de toucinho durante a gestação. Os resultados de ganho de peso das fêmeas durante o período de gestação, em razão da ingestão de proteína e da ordem de parto, são descritos na Tabela 3.

O nível de PB na ração de gestação afetou o ganho de peso da cobertura aos 110 dias de prenhez $(\mathrm{P}<0,05)$, assim como dos 90 aos 110 dias, independentemente da ordem de parto. Contrariamente, Mahan (1998), durante cinco ciclos consecutivos, avaliou o efeito de dois níveis de PB (13,0 vs 
Tabela 3 - Ganho de peso (GP), em kg, e espessura de toucinho (ET), em mm, de porcas alimentadas com rações contendo diferentes níveis protéicos durante a gestação do 10 ao 3으 parto

Table 3 - Values of weight gain (WG) and backfat thickness (BT) of sows fed diet with different protein levels during pregnancy, from the first to third parturition

\begin{tabular}{|c|c|c|c|c|c|c|c|}
\hline \multirow[t]{2}{*}{$\begin{array}{l}\text { Variável } \\
\text { Item }\end{array}$} & \multicolumn{3}{|c|}{$\begin{array}{c}\text { Nível de PB }(\%) \\
\text { Level of } C P\end{array}$} & \multicolumn{3}{|c|}{$\begin{array}{l}\text { Ordem de parto } \\
\text { Farrowing order }\end{array}$} & \multirow[t]{2}{*}{$\mathrm{CV}(\%)$} \\
\hline & 10,0 & 13,5 & 17,0 & $\mathrm{I}$ & II & III & \\
\hline Peso cobertura, kg (Mating weight) & 140,7 & 146,6 & 148,9 & 118,9 & 148,9 & 174,2 & 4,1 \\
\hline GP de $0-60 \mathrm{~d}^{1}, \mathrm{~kg}($ WG from $0-60 \mathrm{~d})$ & 20,25 & 22,96 & 22,17 & $13,20 \mathrm{~b}$ & $27,50 \mathrm{a}$ & $26,30 \mathrm{a}$ & 30,2 \\
\hline GP de $90-110 \mathrm{~d}^{\mathrm{l}}, \mathrm{kg}$ (WG from $90-110 \mathrm{~d}$ ) & $11,04 \mathrm{~b}$ & $13,11 \mathrm{ab}$ & $14,96 \mathrm{a}$ & 12,50 & 11,85 & 14,67 & 45,0 \\
\hline ET no parto ( $B T$ in the farrowing) & 17,00 & 17,87 & 18,13 & 17,47 & 17,33 & 18,21 & 18,2 \\
\hline Ganho na ET, mm (Gain in BT) & 3,14 & 3,19 & 4,42 & 3,60 & 3,14 & 3,92 & 68,2 \\
\hline
\end{tabular}

${ }^{1}$ Médias com letras diferentes na mesma linha diferem $(P<0,10)$ pelo teste SNK.

${ }^{1}$ Means with different letters in row differ $(P<0.10)$ by SNK test.

$16,0 \%$ ) na dieta de gestação e não observou ganho de peso significativo durante a gestação e no intervalo da cobertura aos 110 dias de gestação.

Em muitas situações, as mudanças no peso corporal não são afetadas pela ingestão de proteína durante a gestação. Essa discrepância, segundo Maxwell et al. (1987), provavelmente estaria relacionada à qualidade da proteína, mas sabe-se que, quando as exigências para o desenvolvimento fetal são alcançadas, o animal aumenta seu anabolismo (Close \& Cole, 2001)

O nível de $\mathrm{PB}$ na ração de gestação e a ordem de parto não afetaram $(\mathrm{P}>0,05)$ o ganho em espessura de toucinho pela fêmea durante a gestação. O grupo de porcas do tratamento com 17,0\% de PB na dieta de gestação apresentou maior valor absoluto na ET, o que está coerente com o ganho de peso durante a gestação. Segundo Aherne (1997), para cada $5 \mathrm{~kg}$ de ganho de peso, aumenta-se $0,72 \mathrm{~mm}$ no ponto P2 nos 100 dias de gestação.

Conforme demonstrado na Tabela 4,não foi observada interação significativa $(\mathrm{P}>0,05)$ dos fatores estudados para os parâmetros avaliados durante a lactação.

O GCP não foi afetado pelo nível de proteína ( $\mathrm{P}>0,05)$, mas foi influenciado pela ordem de parto, pois as fêmeas de 1 o e de 20 parto ganharam mais peso que as de 30 parto, assim como as do tratamento com $10,0 \%$ de PB tiveram menor ganho de peso maternal. O aumento do peso da porca durante vários ciclos de gestação é resultado do efeito anabólico deste período e, como observado neste trabalho, a modificação geral de peso foi positiva durante cada ciclo reprodutivo e manteve-se bem acima do valor mínimo preconizado pelo NRC (1998).

O nível de PB na ração de gestação e a ordem de parto não afetaram $(\mathrm{P}>0,05)$ a perda de peso relativo das porcas durante a lactação. Houve perda de peso em todos os tratamentos, no entanto, em valor absoluto, o tratamento com $13,5 \%$ de PB resultou em maior perda de peso no intervalo de 21 dias de lactação, em melhor eficiência energética $(1,25)$ e em menor consumo de ração $(4,2 \mathrm{~kg})$. Do mesmo modo, os fatores avaliados não influenciaram ( $\mathrm{P}>0,05)$ a PET no período parto-desmame, o que pode também ter sido consequiência do grande coeficiente de variação dos dados. Diferentemente da PET, o IDC foi significativo $(\mathrm{P}<0,05)$, sendo inferior para as porcas submetidas ao maior (17\%) e ao menor (10\%) nível protéico. Estes resultados são coerentes justamente porque estes dois grupos de animais apresentaram pouca variação no peso durante a lactação.

O consumo de ração (CR) durante a lactação foi afetado pelo nível de $\mathrm{PB}$ da dieta de gestação e pela ordem de parto $(\mathrm{P}<0,10)$, embora tenha sido inferior ao observado por Mahan (1998). Mesmo assim, o consumo elevou com o aumento da ordem de parto, corroborando as observações de Einarsson \& Rojkittikhun (1993) e Lynch (1989) de que o consumo de ração é baixo no $1 \underline{\mathrm{O}}$ e $2 \underline{\mathrm{O}}$ partos e depois aumenta nos partos subseqüentes. Quando comparado o consumo aos níveis protéicos da ração, observou-se que o grupo de fêmeas com maior peso corporal em todas as medições foi o que apresentou menor consumo. A variação do número de leitões foi reduzida pela equalização da leitegada e, portanto, outras variações como o ganho de peso da leitegada e a própria variação ambiental podem ter modificado o consumo. Todavia, em geral, o consumo da porca na lactação é influenciado positivamente ou negativamente pelo seu peso corporal (Neil et al., 1996).

A eficiência energética (EE) não foi significativa como nos trabalhos de Lima et al. (2002) e Hashimoto et al. (2004), mas, numericamente, apresentou menor valor para o nível de $13,5 \%$ de PB, semelhante aos encontrados por estes autores. 
Tabela 4 - Peso à cobertura (PC), peso ao parto (PP), peso ao desmame (PD), ganho da cobertura ao pós-parto (GCP), peso relativo $(P R)$, eficiência energética (EE), espessura de tocinho (ET) ao parto, ET ao desmame, perda em ET na lactação (PET), PET corrigido, consumo de ração (CR) e intervalo desmame-cobertura (IDC) de porcas submetidas a diferentes níveis protéicos durante a gestação, do 1으 ao 3 으 parto

Table 4 - Weight at farrowing (WF), weight at parturition (WP), weight at weaning (WW), mating gain post-parturition (GMP), relative weight (RW), energy efficiency (EE), backfat thickness (BT) at farrowing, BT at weaning, BT loss in the lactation (LBL), corrected LBL, feed intake (FI), weaningmating interval (IWM) of sows fed diet with different protein levels during pregnancy, from the first to third parturition

\begin{tabular}{|c|c|c|c|c|c|c|c|}
\hline \multirow[t]{2}{*}{$\begin{array}{l}\text { Item } \\
\text { Item }\end{array}$} & \multicolumn{3}{|c|}{$\begin{array}{c}\text { Nível de PB (\%) } \\
\text { Level of } C P\end{array}$} & \multicolumn{3}{|c|}{$\begin{array}{l}\text { Ordem de parto } \\
\text { Farrowing order }\end{array}$} & \multirow[t]{2}{*}{$\mathrm{CV}(\%)$} \\
\hline & 10,0 & 13,5 & 17,0 & I & II & III & \\
\hline $\mathrm{PC}(W F), \mathrm{kg}$ & 140,68 & 146,64 & 148,92 & 118,93 & 148,88 & 174,17 & 4,1 \\
\hline $\mathrm{PP}(W P), \mathrm{kg}$ & 180,96 & 192,25 & 193,75 & 165,57 & 193,15 & 212,96 & 5,6 \\
\hline $\mathrm{PD}(W W), \mathrm{kg}$ & 180,14 & 185,61 & 188,83 & 160,93 & 192,65 & 205,67 & 6,5 \\
\hline $\mathrm{GCP}(G M P), \mathrm{kg}$ & 40,28 & 45,61 & 44,83 & $46,63 \mathrm{a}$ & $44,23 \mathrm{ab}$ & $38,79 b$ & 23,3 \\
\hline $\mathrm{PR}(R W), \mathrm{kg}$ & 99,58 & 96,64 & 101,83 & 97,27 & 99,91 & 100,94 & 13,2 \\
\hline EE & 1,32 & 1,25 & 1,34 & 1,36 & 1,35 & 1,24 & 16,5 \\
\hline ET parto (BT farrowing), $\mathrm{mm}$ & 16,32 & 17,14 & 17,54 & 17,07 & 16,88 & 17,50 & 20,7 \\
\hline ET desmame ( $B T$ weaning), $\mathrm{mm}$ & 14,36 & 14,36 & 14,38 & 14,77 & 13,88 & 14,38 & 17,2 \\
\hline $\operatorname{PET}(L B L), \mathrm{mm}$ & 1,96 & 2,78 & 3,16 & 2,30 & 2,50 & 3,12 & 114,7 \\
\hline PET corrigido $(\text { corrected } L B L)^{2}, \mathrm{~mm}$ & 2,56 & 2,57 & 2,65 & 2,60 & 2,55 & 2,61 & 6,5 \\
\hline $\mathrm{CR}(F I), \mathrm{kg}$ & $4,50 \mathrm{a}$ & $4,21 \mathrm{~b}$ & $4,41 \mathrm{ab}$ & $4,24 \mathrm{~b}$ & $4,32 \mathrm{~b}$ & $4,59 \mathrm{a}$ & 10,2 \\
\hline IDC $(I W M)$, dias & $6,0 \mathrm{ab}$ & $6,3 \mathrm{a}$ & $5,5 \mathrm{~b}$ & 6,17 & 5,85 & 5,79 & 20,3 \\
\hline
\end{tabular}

${ }^{1}$ Médias com letras diferentes na mesma linha diferem $(\mathrm{P}<0,10)$ pelo teste $\mathrm{SNK}$.

${ }^{1}$ Means with different letters in row differ $(P<0.10)$ by SNK test.

Tabela 5 - Número de leitões nascidos totais (NT), número de leitões nascidos vivos (NV), natimortos, número de leitões desmamados (ND), peso médio da leitegada ao nascimento (PMLN), peso médio da leitegada ao desmame (PMLD), peso médio do leitão ao nascimento (PMN), peso médio do leitão aos 7 dias de lactação (P7), peso médio do leitão aos 14 dias (P14), peso médio do leitão ao desmame (PMD), ganho médio diário de peso da leitegada (GDPL) e ganho médio diário de peso do leitão (GDP) de fêmeas suínas alimentadas com rações contendo diferentes níveis protéicos durante a gestação do 1 으 ao 3 으 parto

Table 5 - Total number of born pigs (BT), number of pigs born alive (BA), stillborns, weaned number of pigs (WN), average weight of litter at birth (AWLB), average weight of litter at weaning (AWLW), average weight of pig at birth (AWB), average weight of pigs at 7 days of lactation (W7), average weight of pig at 14 days (W14), average weight of piglet at weaning (AWW), daily average weight gain of litter (DAGL) and daily average weight gain of piglet (DAG) of sows fed diet with different protein levels during pregnancy, from the first to third parturition

\begin{tabular}{|c|c|c|c|c|c|c|c|}
\hline \multirow[t]{2}{*}{ Item } & \multicolumn{3}{|c|}{$\begin{array}{c}\text { Nível de PB \% } \\
\text { Level of } C P\end{array}$} & \multicolumn{3}{|c|}{$\begin{array}{l}\text { Ordem de parto } \\
\text { Farrowing order }\end{array}$} & \multirow[t]{2}{*}{$\mathrm{CV}(\%)$} \\
\hline & 10,0 & 13,5 & 17,0 & I & II & III & \\
\hline $\mathrm{NT}(B T)$ & 10,71 & 10,64 & 11,08 & $10,37 b$ & $10,19 b$ & $11,75 \mathrm{a}$ & 18,0 \\
\hline $\mathrm{NV}(B A)$ & 9,78 & 9,63 & 9,61 & $9,13 b$ & $9,70 \mathrm{ab}$ & $10,33 \mathrm{a}$ & 16,5 \\
\hline Natimortos (Stillborn) & 0,69 & 0,87 & 0,62 & 0,77 & 0,56 & 0,86 & 75,0 \\
\hline $\mathrm{ND}(W N)$ & 9,18 & 9,14 & 9,00 & $8,67 \mathrm{~b}$ & $8,85 b$ & $9,95 \mathrm{a}$ & 16,5 \\
\hline PMLN (AWLB), kg & 14,40 & 14,18 & 15,11 & $13,24 \mathrm{c}$ & $14,70 \mathrm{~b}$ & $15,98 \mathrm{a}$ & 14,4 \\
\hline $\operatorname{PMLD}(A W L W), \mathrm{kg}$ & 49,03 & 50,55 & 49,91 & $46,18 b$ & $48,22 b$ & $56,11 \mathrm{a}$ & 21,7 \\
\hline $\operatorname{PMN}(A W B), \mathrm{kg}$ & 1,48 & 1,48 & 1,56 & $1,42 b$ & $1,54 \mathrm{a}$ & $1,55 \mathrm{a}$ & 12,7 \\
\hline P7 (W7), kg & 2,54 & 2,56 & 2,80 & 2,58 & 2,57 & 2,74 & 14,5 \\
\hline $\mathrm{P} 14(W 14), \mathrm{kg}$ & 3,98 & 3,95 & 4,04 & 3,93 & 3,96 & 4,10 & 13,8 \\
\hline $\operatorname{PMD}(A W W), \mathrm{kg}$ & 5,34 & 5,51 & 5,51 & 5,32 & 5,43 & 5,64 & 15,1 \\
\hline GDPL (DAGL), $\mathrm{kg}$ & 1,65 & 1,73 & 1,66 & $1,57 b$ & $1,60 b$ & $1,91 \mathrm{a}$ & 27,8 \\
\hline $\operatorname{GDP}(D A G), \mathrm{kg}$ & 0,184 & 0,192 & 0,188 & 0,185 & 0,185 & 0,195 & 19,2 \\
\hline
\end{tabular}

${ }^{1}$ Médias com letras diferentes na mesma linha diferem $(P<0,10)$ pelo teste $S N K$

${ }^{1}$ Means with different letters in row differ $(P<0.10)$ by SNK test.

Como descrito na Tabela 5, verificou-se efeito significativo $(P>0,05)$ da interação nível de proteína $\times$ ordem de parto sobre as variáveis relacionadas às características reprodutivas das porcas e ao desempenho das leitegadas. O número de leitões nascidos vivos e o número de nascidos totais, assim como o peso médio do leitão e da leitegada ao nascimento, não foram afetados pelos níveis de $\mathrm{PB}$ na ração de gestação ( $\mathrm{P}>0,05)$. Estudos como o de Balestra et al. (1999) confirmam esta observação e evidenciam que o nível protéico da ração de gestação não afeta o número de leitões nascidos vivos e totais. No entanto, a ordem de parto elevou o número de leitões nascidos totais, de nascidos 
vivos e de leitões desmamados $(\mathrm{P}<0,05)$, elevando progressivamente o número de leitões nascidos com o aumento do número de partos. Há uma tendência de que, quanto maior o número de leitões, menor o peso médio ao nascimento, todavia, esse resultado geralmente ocorre a partir do 50 parto e pode variar entre os animais (Martin, 2004).

O PMN e o PMLN diferiram significativamente $(\mathrm{P}<0,05)$ em função da ordem de parto, mas não em decorrência dos níveis protéicos das rações de gestação. O número de leitões nascidos elevou com o aumento do número de partos e, conseqüentemente, do peso médio da leitegada, pois, com o ganho constante de peso corporal das porcas a cada parto, o peso médio do leitão ao nascimento também elevou.

O menor peso do leitão ao nascimento persistiu por todo o período de lactação, a cada intervalo de semana (7, 14 e 21 dias), evidenciando a máxima de que leitão que nasce pequeno desmama com menor peso. Esta correlação pode ter influenciado numericamente o ganho diário (GDP) dos leitões e da leitegada, mesmo que não tenha havido diferença significativa $(\mathrm{P}>0,05)$ entre as médias de GDP dos tratamentos. A ordem de parto influenciou significativamente $(\mathrm{P}<0,05)$ a variação no ganho diário médio da leitegada, sendo que o maior valor foi observado em leitegadas de terceiro parto.

A ingestão de PB na gestação e a ordem de parto não afetaram $(\mathrm{P}>0,05)$ o peso dos leitões ao desmame. Os valores de peso médio ao desmame mantiveram-se abaixo dos valores comerciais para o período de 21 dias, todavia, embora não tenham sido verificados o nível de infestação e o tipo de agente patogênico, observou-se a presença de diarréia em todas as leitegadas, o que talvez possa explicar o baixo desempenho, pois, segundo Moraes (1993), leitões acometidos por diarréia podem deixar de ganhar diariamente até $0,45 \mathrm{~kg}$ em relação aos sadios.

Em geral, o nível de PB afetou principalmente o ganho de peso da porca durante a gestação, influenciando o CR e o IDC subsequientes, porém não limitou o desenvolvimento dos leitões e tampouco reduziu o desempenho das fêmeas durante a lactação. O desenvolvimento das porcas, assim como o desempenho reprodutivo, melhorou conforme aumentou o número de partos. Não se observou a ocorrência da síndrome do $2 \mathbf{Q}$ parto, pois todas as variáveis que apresentaram diferenças significativas evidenciaram valores superiores aos do primeiro parto, principalmente se considerados os valores numéricos de leitões nascidos e a superioridade do peso ao desmame em relação ao ciclo anterior.

Embora o nível de PB não tenha influenciado globalmente o desempenho das porcas durante três ciclos conse- cutivos, os resultados obtidos para alguns parâmetros avaliados evidenciaram que níveis de proteína preconizados pelo NRC (1998) não atendem às exigências nutricionais de porcas, principalmente no primeiro parto.

\section{Conclusões}

O maior nível de $\mathrm{PB}$ da ração, independentemente da ordem de parto, proporcionou maior ganho de peso da cobertura aos 110 dias de gestação e dos 90 aos 110 dias de gestação e não alterou o ganho em espessura de toucinho nesse período.

O nível de $10 \%$ PB da ração, assim como a ordem de parto, elevou o consumo durante a lactação, mas não houve interação dos fatores. O menor IDC, no entanto, foi obtido com o nível de $17 \%$ de PB na ração.

Porcas de $\mathfrak{1}$ ciclo, em relação às de 20 e 30 ciclos, apresentaram maior ganho de peso, independentemente do nível de proteína na ração. O aumento de peso a cada ciclo consecutivo influenciou o peso médio da leitegada ao nascimento e ao desmame, independentemente do nível de PB da ração de gestação.

A ordem de parto, independentemente do nível de proteína da ração, influenciou o número de leitões nascidos totais, o de nascidos vivos e o de leitões desmamados.

\section{Literatura Citada}

AHERNE, F.X. Nutrition of the early weaned sow. In: WESTERN NUTRITION CONFERENCE, 18., 1997, Winnipeg. Proceedings... Winnipeg: 1997. p.43-61.

BAÊTA, F.C.; SHANKLIN, M.D.; JONHSON, H.D. et al. Equivalent temperature index at temperature above the thermoneutral for lactating dairy cows. American Society of Agricultural Engineers, v.80 p.1-21, 1987.

BELSTRA, B.A.; RICHERT, B.T.; FRANK, J.W. Effect of gestation dietary crude protein level on the gestation and lactation performance of primiparous sows. Swine Day Report, v.3, p1-5, 1998.

CLOSE, W.H.; COLE, D.J.A. Practical feeding strategies. In: CLOSE, W.H.; COLE, D.J.A. (Eds.) Nutrition of sows and boars. Nottingham: Nottingham University Press, 2001. p.293-331.

CROMWELL, G.L. Biological relationship of birth and weaning traits in pigs. Farmer's Pride, KPPA New, v.12, n.47, p.1-8, 2001.

EINARSSON, S.; ROJKITTIKHUN, T. Effects of nutrition on pregnant and lactating sows. Journal Reproduction and Fertility, v.48, p229-239, 1993 (suppl.).

GREENHALGH, J.F.D.; ELSLEY, F.W.H.; GRUBB, D.A. et al. Coordinated trials on the protein requirements of sows. A comparison of four levels of dietary protein in gestation and two in lactation. Animal Production, v.24, p.307-321, 1977.

HASHIMOTO, F.A.M.; FERREIRA, A.S.; DONZELE, J.L. et al. Níveis de proteína bruta na ração de gestação para porcas de segundo e terceiro ciclos reprodutivos. Revista Brasileira de Zootecnia, v.33, n.2, p.365-374, 2004.

LIMA, K.R.S.; FERREIRA, A.S.; DONZELE, J.L. et al. Níveis de proteína bruta da ração para marrãs em gestação. Revista Brasileira de Zootecnia, v.31, n.1, p.86-95, 2002. 
LIMA, G.J.M.M.; VIOLA, E. Nutrição de porcas em lactação: qual a influência sobre o desenvolvimento da leitegada? In: SIMPÓSIO SOBRE NUTRIÇÃO E MANEJO DE LEITÕES, 1998, São Paulo. Anais... São Paulo: 1998. 102p.

LYNCH, P.B. Voluntary feed intake in gilts and multiparous sows. In: FORBES, J.M.; VARLEY, M.A.; LAWRENCE, T.L.J. (Eds.) The voluntary fee intake of pigs. Edinburg: British Society of Animal Production, 1989. p.61-70. (Occasional Publication, 13)

MAHAN, D.C. Effect of feeding various gestation and lactation dietary protein sequences or long-term reproductive performance in swine. Journal of Animal Science, v.45, p.1061-1072, 1977.

MAHAN, D.C. Relationship of gestation protein and feed intake level over a five-parity period using a high-producing sow genotype. Journal of Animal Science, v.76, p.533-541, 1998.

MAHAN, D.C. Effect of dietary protein sequences on long term sow reproductive performance. Journal of Animal Science, v.49, p.514-522, 1979.

MARTIN, A.A. When should sows be weaned? Oak Park: Carlow: Irish Agriculture and Food Development Authority. 2004. $4 \mathrm{p}$.

MAXWELL, C.V.; JOHNSON, R.K; LUCE, W.G. Effect of protein and supplemental choline on reproductive performance of gilts fed sorghum diets. Journal of Animal Science, v.64, p.10441050, 1987.

MORAES, N. Fatores que limitam a produção de leitões na maternidade. Suinocultura dinâmica. Concórdia: EMBRAPACNPSA, 1993. 6p. (Boletim Informativo, 9)

MULLAN, B.P. The catabolism of fat and lean by sows during lactation. Pig News and Information, v.12, p.221-225, 1991.
NATIONAL RESEARCH COUNCIL - NRC. Nutrient requirements of swine. 9.ed.rev. \{S.I\}: National Academy Press, 1998. 188p. NEIL, M.; OGLE, B.; ANNER, K. A two diet system and ad-libitum feeding of the sow. I. Sow performance. Animal Science, v.62, p.337-347, 1996.

PATIENCE, J.F. Meeting the energy and protein requirement of high producing sow, Animal Feed Science Technology, v.58, p.49-64, 1996.

PETTIGREW, J.E.; YANG, H. Protein nutrition of gestation sows. Journal of Animal Science, v.75, p. 2723-2730, 1997.

PUSEL, V.G.; JONHSTON, L.A. Freezing of board spermatozoa:fertilizing capacity with concentrated semen and a new thawing procedure. Journal of Animal Science, v.40, p.99-102, 1975 .

ROPPA, L. Manejo e nutrição da fêmea suína. Disponível em: <www.porkworld.com.br.> Acesso em: 21/02/2001.

STATISTICAL ANALYSIS SYSTEM - SAS. SAS language reference. Version 8, Cary: 2001. 1042p.

WHITTEMORE, C.T. Nutrition reproduction interaction in primiparous sows. Livestock Production Science, v.46, p.65-83, 1996.

YANG, H.; EASTHAM, P.R.; PHILLIPS, P. et al. Reproductive performance, body weight, and body condition of breeding sows with differing body fatness at parturition, differing nutrition during lactation and differing litter size. Animal Production, v.48, p.181-201, 1989.

Recebido: 11/11/04 Aprovado: 29/05/06 